\title{
COLHEITA MECÂNICA E MANUAL DA CANA-DE-AÇÚCAR: HISTÓRICO E ANÁLISE
}

SILVA, Fernando Igor Campos ${ }^{1}$

GARCIA, Anice ${ }^{2}$

Recebido em: $2008-10-23$

Aprovado em: 2009-03-09

ISSUE DOI: $10.3738 / 1982.2278 .149$

RESUMO: A cana-de-açúcar é economicamente uma das mais importantes culturas do Brasil. Hoje, a agroindústria canavieira processa cerca de 300 milhões de toneladas de cana-de-açúcar por ano, produzidos em aproximadamente 5,4 milhões de hectares. Embora a área colhida mecanicamente seja inferior a $25 \%$, essa tende a aumentar rapidamente principalmente devido a leis governamentais. A adoção desse sistema de colheita causa entre outros o aumento dos índices de impureza na carga e perdas de cana no campo. O objetivo do presente trabalho foi o de fazer um levantamento e comparar potencialidades e desvantagens dos tipos de colheita para a cultura de cana-de-açucar.

Palavras-chave: Colheita. Cana-de-açúcar. Histórico e análise.

\section{HARVEST MECHANICS AND MANUAL OF THE CANA-DE- AÇÚCAR: DESCRIPTION AND ANALYSIS}

SUMMARY: The sugarcane is one of the most important crops for Brazilian commercial terms. Nowadays the sugarcane agro-industry processes around 300 million tons of sugarcane a year, produced in approximately 5,4 million hectares. Although the mechanized harvested area is less than $25 \%$, it tends to increase in nest years, especially due to governmental laws. The adoption of the mechanized harvesting system causes among others the raise of strange matter and loss of raw material in the field.

Keywords: Harvest, Sugarcane, Historical . Analysis

\section{INTRODUÇÃO}

A cana-de-açúcar (Saccharum spp.) esta entre as culturas mais importantes do agronegócio brasileiro. O Brasil é o maior produtor mundial de açúcar e de álcool de cana-de-açúcar e destaca-se também como o maior exportador, sendo o Estado de São Paulo o maior produtor nacional.

As operações de colheita de cana-de-açúcar foram classificadas por Ripoli (1996) em três subsistemas distintos: manual, semi-mecanizado e mecanizado. Tal classificação deve-se ao fato da existência de um sistema global que envolve o corte e 
o carregamento, o transporte e a recepção da matéria prima. O subsistema mecanizado diferencia-se por as operações de corte, carregamento e transporte ocorrerem exclusivamente por meio de maquinas.

$\mathrm{Na}$ tentativa de reduzir custos e melhorar a rentabilidade do setor, as usinas, a exemplo do que ocorreu nas demais culturas, têm optado por um sistema gradual de mecanização, principalmente da colheita. Da área do Estado de São Paulo, segundo a ALCOOLBRAS (2003), apenas 30\% foram colhidos por maquinas na safra de 2003, sendo que esse percentual tende a aumentar rapidamente nos próximos anos devido a vários fatores, como custos de colheita e escassez de mão-de-obra.

O objetivo do presente trabalho foi o de fazer um levantamento e comparar potencialidades e desvantagens dos tipos de colheita para a cultura de cana-de-açucar.

\section{REFERENCIAL TEÓRICO}

A cana-de-açúcar (Saccharum sp.) é uma gramínea originária da Ásia, que foi trazida para o Brasil da Ilha da Madeira em 1535. Cultivada inicialmente no Nordeste, verificou-se uma rápida adaptabilidade dessa gramínea ao solo e clima da região. Em Alagoas, essa cultura começou a prosperar em meados de 1835, embora a maior expansão tenha se verificado em 1849/59. (PROJETOCALYPSO, 2007) Hoje, os maiores produtores são Brasil, Índia, Cuba México e China. (BAHIA, 2007).

A cana-de-açúcar é cultivada numa extensa área territorial, compreendida entre os paralelos $35^{\circ}$ de latitude Norte e Sul do Equador, apresentando melhor comportamento nas regiões quentes. O clima ideal é aquele que apresenta duas estações distintas, uma quente e úmida, para proporcionar a germinação, perfilhamento e desenvolvimento vegetativo, seguido de outra fria e seca, para promover a maturação e conseqüente acúmulo de sacarose nos colmos (AGROBYTE, 2007).

Solos profundos, pesados, bem estruturados, férteis e com boa capacidade de retenção são os ideais para a cana-de-açúcar que, devido à sua rusticidade, se desenvolve satisfatoriamente em solos arenosos e menos férteis, como os de cerrado. Solos rasos, isto é, com camada impermeável superficial ou mal drenada, não devem ser indicados para a cana-de-açúcar (AGROBYTE, 2007).

Até pouco tempo, o setor usineiro dependia exclusivamente da mão-deobra humana para realizar o corte da cana-de-açúcar. Eram famílias inteiras de 
trabalhadores rurais que passam horas todos os dias, enfrentando as condições mais adversas para desempenhar seu trabalho. Só que de uns tempos para cá, o processo de colheita da cana passa por um intenso processo de mecanização. Essa mudança de perfil, onde o homem esta cedendo, gradualmente, lugar a maquina, faz, em partes, a colheita nas lavouras de cana-de-açúcar ficar mais eficientes (CANA..., 2005).

No processo de produção da cana, a colheita se destaca pelos altos custos envolvidos e dificuldades operacionais, seja ela conduzida de forma manual, semi-mecanizada ou mecanizada. Nos últimos anos, a colheita tem passado por uma fase de substituição do corte manual para o mecanizado e, de acordo com Nunes Junior et al. (2005), 38,8\% da produção de cana da safra 2003/2004 da região centro-sul do pais foi colhida mecanicamente e destas, $40,7 \%$ na forma picada e crua. Existe a perspectiva desses percentuais aumentarem nos próximos anos devido ao custo, escassez de mão-de-obra e pela legislação ambiental, que reduz gradativamente a queima de canaviais, inviabilizando a colheita manual.

Para trabalhar com segurança em culturas semi-mecanizadas, que constituem a maioria das nossas explorações, a declividade máxima deverá estar em torno de 12\%; declividades acima desse s limite apresentam restrições às práticas mecânicas, para culturas mecanizadas, com adoção de colheitadeiras automotrizes, o limite máximo de declividade cai para 8 a 10\%. (AGROBYTE 2007).

A mecanização total ou parcial se apresenta atualmente como a única opção para a colheita da cana, tanto do ponto de vista ergonômico quanto econômico e, principalmente, do ponto de vista legal e ambiental, já que apenas o corte mecânico viabiliza a colheita sem queima previa, o que por sua vez viabiliza o aproveitamento do palhiço. A evolução lenta da colheita mecânica no País permite concluir, mesmo sem abordar detalhes técnicos, que as soluções tecnológicas disponíveis não são suficientemente competitivas para atrair os usuários, ou seja, existem limitadores que restringem sua implementação. (MAGALHÃES; BRAUNBECK, 1998).

Esta abordagem tem implicações profundas nos processos convencionais de colheita, tanto manual quanto mecânica, implicações estas associadas com perdas de cana, contaminação de cana e palhiço com impurezas minerais, altos investimentos para a colheita e a recuperação do palhiço assim como inviabilidade econômica do despalhamento manual. 
No âmbito da produção agrícola, é importante que se reconheça que $60 \%$ do custo de produção do etanol e açúcar é representado pela matéria-prima, sendo o restante representado pelo processamento e custos administrativos, de transporte e de distribuição. Neste âmbito, a colheita mecanizada da cana, que tem crescido nos últimos anos, é tema importante e altamente relevante. Atualmente, $40 \%$ da área colhida de cana-de-açúcar utiliza o processo mecanizado de colheita, com ou sem queima previa para limpeza do canavial, principalmente em áreas com topografia adequada e com problemas relacionados a disponibilidade de mão-de-obra. Contudo, a adoção do sistema mecanizado de colheita de cana picada introduz certos inconvenientes, tais como aumento dos índices de impurezas na carga, que implicam a redução da qualidade tecnológicas da matéria-prima fornecida para moagem e perdas de cana no campo (MAGALHÃES; BRAUNBECK, 1998).

Segundo Moraes (1992), a cana colhida por colhedoras de cana picada apresenta índices de impurezas 2,7 vezes maiores que a cana cortada manualmente e carregada mecanicamente. Kroes; Harris (1996) destacam que a utilização do corte mecânico pode causar perdas de cana e de caldo e danos na base da soqueira, que reduzem consideravelmente a brotação e proporcionam o ataque de doenças e pragas, refletindo na perda de produtividade da safra subseqüente.

Neves et al. (2004), realizando ensaios com monitor de perdas durante a colheita, relatam que as perdas visíveis no campo foram da ordem de 5\%, verificando-se a correspondência do aumento das perdas de pedaços de cana com o acréscimo da rotação do extrator primário. Também informam que, em todos os ensaios, a incidência de impurezas na carga diminui, a massa foliar no campo aumentou e a carga transportada foi maior no campo aumentou e a carga transportada foi maior com o aumento da rotação do extrator primário.

A adoção do sistema preconizado de colheita introduziu certos inconvenientes, tais como o aumento dos índices de matéria estranha na carga, o que, por sua vez, implicam a redução da qualidade tecnológicas da matéria-prima fornecida para moagem e perdas de cana no campo (FERNANDES et al., 2000).

$\mathrm{Na}$ colheita mecânica de cana crua, em que não se queima o canavial para efetuar uma pré-limpeza nas canas, os índices de perdas e de matéria estranha tendem a aumentar devido a maior massa vegetal que será processada pela colhedora. As perdas de cana-de-açúcar podem ser divididas em perdas visíveis e invisíveis, em que as primeiras são aquelas que podem ser detectada visualmente no campo após a 
colhedora, podendo ser colmos inteiros e/ou suas frações, rebolos e tocos resultantes no corte basal, enquanto as perdas invisíveis são na forma de caldo, serragem e estilhaços de cana que ocorrem em razão da ação dos mecanismos rotativos que cortam, picam e limpam a cana que ocorrem em razão da ação dos mecanismos rotativos que cortam, picam e limpam a cana durante o processamento interno nas colhedoras (RODRIGUES, 2008).

A tentativa de reduzir os índices de matéria estranha na cana colhida, aumentando-se a rotação dos extratores/ventiladores das colhedoras, pode elevar as perdas de matéria-prima para níveis inaceitáveis economicamente. Por outro lado, o sistema de extratores e/ou ventiladores, responsável pela maior demanda de potencia disponível no motor, é o ponto principal de ocorrência de perdas de matéria-prima (YOUNGER, 1980) Segundo Moraes (1992) pelos levantamentos de dados de perdas totais e, no extrator primário da colhedora, responsável pela limpeza, as perdas invisíveis foram da ordem de $2 \%$ e rebolos, lascas, serragem e caldo.

As perdas e a contaminação da cana-de-açúcar com terra durante o processo de colheita, estão associadas diretamente ao acompanhamento inadequado do perfil solo e da varredura ineficiente, realizada pelo cortador basal (VOLPATO et.al, 2002; OLIVEIRA, 2003, citados por OLIVEIRA, et al., 2007). Em certos casos, essas perdas chegam a $10 \%$ e as quantidades de terra incorporadas aos colmos estão entre 3 a $5 \mathrm{~kg} \mathrm{t}^{1}$ (BRAUNBECK, 1999). A cana contaminada com impurezas durante a colheita reduz, ao ser processada na Usina, as eficiências de filtragem e clarificação do caldo, parâmetros esses ligados a qualidade final do açúcar (RIDGE; DICK, 1992).

A redução de perdas e a contaminação com terra pelo cortador, requerem alterações neste mecanismo, haja vista que mudanças operacionais dos equipamentos existentes, sistematização dos terrenos não reduziram, de forma efetiva, a contaminação dos colmos ao longo da pratica da colheita mecanizada (BRAUNBECK et al., 1999, citados por OLIVEIRA et al, 2007). A solução para este impasse tecnológico esta na utilização de mecanismo passivos ou ativos, capazes de realizar um seguimento do perfil do solo e uma varredura das plantas acamadas de forma eficiente (BRAUNBECK; MAGALHÃES, 2002, citados por OLIVEIRA et al, 2007).

O método automatizado, sem o uso do fogo, é uma técnica viável para a canavicultura brasileira, porque reduz o impacto ambiental e o processo tem uma serie de vantagens, como o rendimento operacional. Uma colhedora, por exemplo, produz o equivalente a 80 homens por dia, alem de poder trabalhar durante $24 \mathrm{~h}$. Foi verificado 
que a colheita mecanizada sem a queima da palhada impedia o crescimento de varias espécies de plantas daninhas, levando consequentemente ao um uso menor de herbicidas para o controle das pragas, o processo mecânico, por não utilizar o fogo, contribuía para uma menor perda de água do solo, aumentava a reciclagem de nutrientes e elevava a quantidade de microorganismos existentes na terra.

Segundo Mello (2006), a colheita manual favorece a diminuição das perdas decorrentes do corte desigual das colhedoras. Estudos mostram que na colheita feita com a foice as perdas raramente ultrapassam 5\%. Já com as maquinas esse percentual pula para $15 \%$, fato que se reflete diretamente na produtividade. Os prejuízos advindos dessa prática, também não são pequenos. Considerando que a área plantada no estado São Paulo, é de aproximadamente três milhões de hectares e a produtividade esta próxima das 100 toneladas/ há, esse percentual equivale a uma perda anual para o setor de R $\$ 20$ milhões.

As curvas de nível e áreas com declives acentuados são um problema para as colhedoras, pois a grande parte dos equipamentos são ajustados para o corte numa altura de $30 \mathrm{~cm}$ rente ao solo. "As usinas atualmente na tentativa de diminuir suas perdas estão realizando um corte rente ao solo, muitas vezes, fazendo os facões arrancarem tudo que estiver na frente, inclusive, pedra e outros detritos". O pesquisador tenta provar que esse toquinho de cana, não colhida, que fica na superfície do solo, potencializa a rebrota da próxima safra. Segundo ele, isso acontece porque os açucares que ficam nas plantas servem de armazém natural para manter a planta no período de inverno. "A cana-de-açúcar é uma espécie que possibilita entre 4 e 5 rebrotas, ou seja, ao longo da vida dessa planta é possível o produtor recuperar seu investimento na melhora das condições gerais da sua lavoura”. A pesquisa ainda não foi concluída, no entanto, ele afirma que já existem números que possível elevar o corte sem causar problemas de perdas na produtividade.

Um novo sistema de corte de cana-de-açúcar para a colheita mecanizada, desenvolvido no Instituto Agronômico (IAC) de Campinas, no interior de São Paulo, conseguiu reduzir as perdas da matéria-prima no campo. "O sistema é composto de lâminas serrilhadas, acopladas de forma inclinada aos discos de corte de base utilizados nas máquinas usadas para colher a cana", (CANA..., 2005). As colhedeiras existentes no mercado trabalham com sistema de corte de base por impacto.

Essas máquinas cortam abaixo da superfície do solo, aumentando o desgaste das laminas. O processo também causa perdas e danos às raízes e, com isso, uma rebrota 
menos vigorosa. O novo sistema utiliza o corte por deslizamento com laminas, evitando assim o contato do instrumento com o solo. O resultado é a diminuição nas perdas de cana e nos danos às raízes, o que favorece a rebrota e reduz o desgaste das laminas. A moldagem dos instrumentos foi feita em parceria com a empresa Duraface, que licenciou a patente da invenção do IAC. A previsão é de que até abril do ano que vem o produto esteja no mercado.

As perdas de cana-de-açúcar durante a colheita mecanizada podem ser divididas em visíveis e invisíveis. Ripoli; Ripoli (2004). diz que as perdas são denominadas visíveis quando podem ser detectadas visualmente e representam a massa industrializável, isto é, conteúdo em açúcar que fica no campo após a passagem da maquina e constituído-se principalmente de canas inteiras, rebolos e tocos resultantes da altura do corte basal. Estas perdas podem ser facilmente determinadas por coleta manual.

Estas perdas podem ser quantificadas pela demarcação de uma área no terreno, logo após a colheita recolhendo-se os colmos, inteiros ou frações, rebolos e frações de rebolos e tocos resultantes da regulagem deficiente da altura do corte de base. Após a coleta o material deve ser pesado e relacionando-se com a área demarcada, obtém-se as perdas por área.

As perdas decorrentes do processamento da cana-de-açúcar (mecanismos rotativos de corte e limpeza) na forma de caldo, serragem e estilhaços de cana, são denominados perdas invisíveis. Uma regulagem adequada dos extratores, para que a colhedora opere num ponto ótimo, deve conjugar nível baixo de perdas com níveis aceitais de impurezas, pois uma má regulagem da velocidade de saída de ar dos extratores/ ventiladores das colhedoras pode elevar as perdas a níveis muito altos.

A maior dificuldade na avaliação das perdas invisíveis encontra-se na coleta dos fragmentos de rebolos de cana que são atirados pelos extratores das colhedoras. Uma forma de se avaliar as perdas invisíveis é amostrar a área de interesse antes da colheita por meio do corte manual de fileiras de colmos, estimando-se a produtividade e posteriormente comparando-se com as perdas visíveis a matéria-prima que foi levada a unidade industrial. Neste caso devemos considerar que as características vegetativas encontradas nas fileiras podem ser extrapoladas para a área, embora várias apresentassem resultados de diversas variedades de cana-de-açúcar, sobre a variabilidade espacial referente ao numero médio de 7 a 16 colmos industrializáveis por metro linear de fileira de plantio, no momento da operação de colheita. 
Burleigh et al. (1988) comenta que as perdas invisíveis raramente são consideradas na literatura devido a impossibilidade de quantificá-las no campo, apesar de se constituírem como característica importante na colheita de cana picada.

Outros fatores podem influenciar nas perdas na colheita mecanizada como: variedade, tratos culturais, preparo de solo, manutenção da colhedora, habilidade do operador, falhas na cultura, porte do canavial, entre outros.

Com o aumento da velocidade de deslocamento da colhedora, as perdas aumentam, mas estudos conduzidos mostraram que os índices de perdas visíveis com três diferentes colhedoras, sob mesmas condições de campo não apresentaram diferenças estatísticas significativas.

Segundo Magalhães; Braunbeck (1998), nos últimos anos tem crescido o interesse pela colheita de cana-de-açúcar por colhedoras de cana picada, principalmente em áreas com topografia adequada e problemas relacionados a mão-de-obra. Para Fernandes et al. (1977), a adoção dessa modalidade de colheita introduz certos inconvenientes, tais como: aumento dos índices de impureza na carga, que implicam na redução da qualidade tecnológica da matéria prima fornecida para moagem e perdas de cana no campo. Consideram-se como impurezas toda a matéria estranha ao processamento industrial da cana-de-açúcar, ou seja, que não se prestam a extração de açúcar ou de álcool. Geralmente, as impurezas vegetais como folhas, ponteiros e raízes compreendem a maior porcentagem de impurezas nas cargas transportadas a usina, seguidas pelas impurezas minerais como terra, pedras e eventuais pedaços de metal.

A qualidade tecnológica da cana-de-açúcar implica que, para o processamento industrial, o colmo deve estar maduro, sadio e limpo, sendo a cana madura aquela que atingiu seu potencial máximo de acúmulo de sacarose, (FERNANDES, 1988) Colocando-se a parte as particularidades e a eficiência da usina ou destilaria, o rendimento da recuperação de açúcar ou de álcool estará na dependência direta da qualidade tecnológica da matéria-prima.

$\mathrm{Na}$ colheita mecânica de cana crua, em que não se queima o canavial para efetuar uma pré-limpeza nas canas, os índices de perdas e impurezas tendem a aumentar devido a maior massa vegetal que será processada pela colhedora.

Segundo Younger (1980), a tentativa de reduzir os índices de impureza na cana colhida por meio do aumento da velocidade de saída de ar dos extratores/ventiladores das colhedoras, pode elevar as perdas de matéria-prima em níveis inaceitáveis. Por 
outro lado, o sistema de extratores e/ou ventiladores é responsável pela maior demanda de potencia disponível no motor, alem de ser o ponto principal de ocorrência de perdas de matéria-prima. Dick (1986) afirma que um ajuste nos extratores que permita a colhedora operar num ponto ótimo em relação as perdas e impurezas, é difícil de avaliar com precisão no campo, em razão da dificuldade de coletarem os fragmentos de rebolos de cana que são atirados pelos extratores das colhedoras.

Moraes et al. (1992), em um levantamento de dados de perdas visíveis e invisíveis no processamento de cana-de-açúcar pelas colhedoras comercias de cana picada, observe a media de perdas totais (visíveis e invisíveis) de $10 \%$, sendo somente no extrator primário da colhedora responsável pela limpeza, as perdas invisíveis chegam a ordem de $2 \%$ (estilhaços, serragem e caldo).

Segundo Ripoli (1996), para qualificar a quantidade do processamento realizado pelas colhedoras, é preciso quantificar as perdas de matéria prima industrializável que fica no campo após a passagem de maquina. Segundo o autor, existem dois métodos para determinar essas perdas, o direto e o analítico. Pelo método direto, quantifica-se a matéria-prima perdida no campo por catação manual de todas as porções que se encontram em uma determinada área. Pelo método analítico, as perdas são avaliadas confrontando-se a quantidade de matéria prima industrializável, contida no produto in natura, com aquela recolhida no veiculo de transporte, determinada por catação manual na carga, vertida sobre uma lona. A desvantagem do método direto é que são computadas apenas as perdas visíveis; no método analítico é que se trata apenas de uma estimativa de perdas totais sem poder identificar as várias porções da perda total, ou identificar pontos críticos na máquina.

Portanto, para avaliar a magnitude das perdas invisíveis e os índices de impureza vegetais na carga em diferentes ajustes dos extratores das colhedoras de cana picada, torna-se necessária a determinação desses parâmetros em condições controladas de laboratório.

A colheita mecanizada da cana-de-açúcar esta cada vez mais presente nos sistemas de produção no Brasil. No sistema de colheita mecanizada sem queima, as folhas, bainhas, ponteiros, alem de quantidade variável de pedaços de colmo são cortados, triturados e lançados sobre a superfície do solo, formando uma cobertura de resíduo vegetal (mulch) denominado palha ou palhada. 
$\mathrm{Na}$ colheita mecanizada de cana-de-açúcar existem algumas peculiaridades relacionadas as interações solo-maquina-planta, que tem causado preocupações, devido as perdas de cana no campo, redução da qualidade da matéria-prima e a redução da longevidade do canavial. Um dos componentes da colhedora que originam esses problemas é o cortador de base.

De acordo com Ueno; Izumi (1995) perdas de 10 a 15\% são freqüentes quando a cana é colhida crua (sem queima previa). Kroes (1997) mostrou que os danos causados pelo cortador de base é o maior problema das colhedoras.

O trabalho de Kroes (1997) mostrou que, com o presente desenho do cortador de base, é impossível evitar tais perdas e danos. Portanto, os atuais cortadores de base das colhedoras de cana, alem de causarem um alto volume de perdas de cana, também provocam redução na produtividade potencial devido aos danos ocasionados na soqueira.

Mello; Harris (2003) define, como alternativa para o corte por impacto, o corte por deslizamento (slicing cut). Segundo Person (1987) se houver um ângulo obliquo entre a lamina e o material a ser cortado, ocorrera também um deslizamento e, estando o material aderido a lamina, este será rompido por fricção.

Segundo Kroes (1997) o corte por deslizamento não se aplica a cortadores de base para colhedoras de cana-de-açúcar, pois estes trabalham rente ou abaixo da superfície do solo, sendo impossível manter o perfil das laminas amolados e , nestas condições, a cana acaba escorregando ao longo da lamina sem ser cortada adequadamente.

O tipo de colheita da cana-de-açúcar pode influenciar a produção e longevidade da cultura, os atributos físicos, químicos e biológicos do solo, o meio ambiente e a saúde publica. O sistema de colheita por cana queimada elimina a matéria seca e aumenta a concentração de gás carbônico na atmosfera, contribuindo com o efeito estufa e diminuindo o teor de matéria orgânica no solo.

A melhoria da qualidade do corte e da matéria-prima é sugerida por meio de intervenções na colheita e em outras praticas culturais existentes como no preparo do solo, plantio, distancia entre sulcos; e de mudanças nos projetos das colhedoras (RIDGE, 1980). Atualmente os fabricantes de colhedoras estão disponibilizando no mercado sistemas e dispositivos para auxiliar o operador no controle da altura do corte de base. 
O sistema de preparo do solo e plantio surge como um dos aspectos mais importantes em relação ao corte basal. A medida que na área aumentam os desníveis, buracos, presença de obstáculos como pedras e tocos, também aumentam as dificuldades de operação das colhedoras, refletindo em maiores perdas de matériaprima, aumento nos percentuais de matéria estranha e de manutenção das maquinas (VOLPATO, 2002).

Apesar de o conjunto cortador basal possuir acionamento hidráulico permitindo variações na altura do corte, ele é projetado para cortar colmos em um ponto um pouco acima do nível do terreno, com a touceira devendo estar sobre um leve camalhão. Essa condição é raramente encontrada, pois as praticas de preparo do solo em uso no Brasil não estão voltadas para a colheita mecanizada (VOLPATO, 2001; RIPOLI; RIPOLI, 2004).

As características morfológicas e fisiológicas das variedades interferem no corte mecânico de cana. Em principio, as colhedoras operam melhor em canas eretas, vigorosas e de sistema radicular profundo. As canas eretas facilitam o corte, da base e do topo, havendo com isso, um ganho na capacidade de trabalho da maquina, pois a colheita ocorre sem maiores interrupções, acarretando em menores perdas em canas não cortadas e melhor limpeza. As canas devem ser vigorosas e com sistema radicular profundo porque o corte mecânico basal resulta na ação de laminas em rotação e exigem certa resistência de sustentação dos colmos para ocorrer o cisalhamento adequado.

A alta produtividade de colmos, acima de 120, 0 t/ha, pode reduzir a capacidade de trabalho de determinadas colhedoras, em função da necessária redução da velocidade de deslocamento. A cana acamada e/ou entrelaçada, proporciona um aumento da probabilidade de embuchamento e de perdas. Se a colheita for em cana crua, esses efeitos negativos são acentuados (RIPOLI; RIPOLI, 2004)

\section{CONSIDERAÇÕES FINAIS}

A colheita mecanizada de cana-de-açúcar, desde que sejam tomados os devidos cuidados para minimizar perdas, apresenta-se como uma técnica promissora ao substituir a manual, tanto em relação a preservação do meio ambiente, quanto em relação a velocidade de colheita, o que acaba se traduzindo em desempenho econômico. Entretanto, devido ao alto custo de implantação e a problemas com relação 
a compactação do solo, deve-se avaliar caso a caso a viabilidade ou não desse tipo de colheita.

\section{REFERÊNCIAS}

AGRIANUAL 2007: anuário da agricultura brasileira: IFNP consultoria \& comércio. 2007.p.516.

AGROBYTE.Cana. Disponível em:<http://www.agrobyte.com.br/cana.htm> Acesso em: 26 fev. 2007, 16:00.

AGROCLUBES.Ficha_técnica.Disponive,emhttp://www.agroclubes.com.br/ficha_tecni ca/fichas.asp?ficha=884\&codigo_produto=884). Acessado em:22 ago.2007,16h15min

AGRONLINE.Noticias.disponível,em:<http://www.agronline.com.br/agronoticias/noticia. php?id=703>.Acessado em:23 maio, 2007, 20h50min

ALCOOBRÁS. Uma safra recorde. Alcoobrás, São Paulo, n.82, p.62-4, nov-dez. 2003.

BAHIA. Cana. Disponível em <http//www.bahia.ba.gov.br/Seagri/cana1.htm>acesso em:23maio,20h50min.2007

BRAUNBECK, O. et al.. Prospects for green cane harvesting and cane residue use in Brazil. Biomass and Bioenergy, v. 17, n.6, p. 495-506, 1999.

BRAUNBECK, O. A.; BAUEN, A.; Rosillo-Calle, F.; Cortez, L. A.Prospects for green cane harvesting and cane residue use in Brazil. Biomass and Bioenergy. England, v.17,n.1,p.495-506, 1999.

BRAUNBECK, O. A.; MAGALHÃES, P. S. G. Seguimento do perfil do solo no corte e/ou levantamento de produtos agrícolas rasteiros. Revista Brasileira de Engenharia Agrícola e Ambiental, Campina Grande, v.6,n.1,p.151-158, 2002.

BRAUNBECK,O. A. Proposta brasileira de colheita mecanizada. In: SEMINÁRIO SOLUÇÕES E NOVIDADES NA MECANIZAÇÃO DA CANA-DE-AÇÚCAR, 1,1999, Ribeirão Preto. Anais...1999 Ribeirão Preto:IDEA, 1999.p.56-60

BURLEIGH et al.. A comparative evaluation of sugarcane harvesting and transport systems for use in the Brazilian sugar industry. São Paulo: Copersucar, 1998. 54p. ( Relatorio Tecnico - copersucar).

CANA: colheita mecanizada. Revista Rural, v. 92, out. 2005. Disponível em <http:// www.revistarural.com.br/Edicoes/2005/artigos/rev92_cana.htm> Acesso em: 23maio 2005. 21h20min. 2005. 
CEDDIA, M. B. et al. Sistema de colheita da cana-de-açúcar e alterações nas propriedades físicas de um solo Podzolico amarelo no estado do Espírito Santo. Pesq. Agropec. bras., Brasília, v.34, n.8, p.1467-1473, ago.1999

DICK, R. G. Australian cane harvest research: Past, present and future. In: International Society Of Sugar Cane Technologists, 19., 1986, Jakarta. Proceedings...Jakarta: International Society of sugar cane Technologists, 1986.v.3, p.1184-221

FERNANDES, A.C. Qualidade tecnologica da cana de açucar. Piracicaba: CTC/Copersucar, 1988. 88p.(Relatório técnico de Circulação Interna)

FERNANDES, A. C..; OLIVEIRA, E. R.; QUEIROZ, L. Sugarcane trash measurements in Brazil. In: International Society Of Sugar Cane Technologists Congress,16., 1977, São Paulo. Proceedings... São Paulo: InternationalSociety of Sugar Cane Technologists, 1978.v.2, p.1963-73.

FERNANDES, A. J. Manual da cana de açúcar. Piracicaba: Livroceres, 1984. p.40.

FERNANDES, R. A. T.; MILAN, M.; PECHE FILHO, A. Gerenciamento da qualidade em operações mecanizadas de um sistema de produção de cana-de-açúcar. Eng. Agric, Jaboticabal, v.20,n.3, p.215-20, 2000.

FURLANI NETO, U. L. Colheita mecanizada da cana de açúcar STAB: açúcar, álcool e subprodutos. Piracicaba, 12, n.3, jan./fev.1994.

KROES, S. The cutting of sugarcane. 1997. 356p. Thesis (Ph.D) - University of Southern Queensland, Toowoomba, 1997.

KROES, S.; HARRIS, H.D. Knockdown causes major damage to cane during harvesting. In:Australian Society Of Sugar Cane Technologists Conference, 18., 1996, Mackay. Proceedings... Brisbane: Watson Fergunson, 1996. p.137-44

MAGALHÃES, P. S. G.; BRAUNBECK, O. A. Colheita de cana-de-açucar- atualidades e perspectivas Organizado por: R H Balbuena; Sergio Hugo Benez; Daniel Jorajuria. Ingenieria Rural y Macanizacion Agrária em el Âmbito Latinoamericano. La Planta: Universidade Nacional de La Plata, 1998.v.1, p.262-73

MELLO, R. C. Improvements in basecutter desing and cane feeding. 2003. 220p. Ph. D. (Thesis). University of Sounthern Queensland. Toowoomba.

MELLO, R. C.; HARRIS, H.. Desempenho de cortadores de base para colhedoras de canade-açúcar com laminas serrilhadas e inclinadas. Revista Brasileira de Engenharia Agrícola e Ambiental, Campina Grande, PB, DEag/UFCG, v.7, n.2, p.355-358, 2003.

MELlO, R. C.. Centro de Engenharia Agricola IAC. Pesquisa FAPESP. ed. 127, set. 2006.

MIALHER,P. Manual de mecanização agrícola. São Paulo: Agronômica Ceres, 1974. $301 \mathrm{p}$. 
MORAES, E. E. Avaliação das perdas invisiveis de cana-de-açucar (Saccharum spp.) e impurezas vegetais na colheita mecanizada. 1992. 124p.. Dissertação (Mestrado em Máquinas Agrícolas)- Faculdade de Engenharia Agrícola. Universidade Estadual de Campinas.

NEVES, J. L. M. et al. Sistema de monitoramento de perdas visíveis de cana-de-açúcar em colhedora de cana picada. Eng. Agríc., Jaboticabal v.24, n.3, p.764-770, set./dez. 2004

NEVES, J. L. M. et al. Avaliação de perdas invisíveis de cana-de-açúcar nos sistemas da colhedora de cana Picada. Eng. Agríc., Jaboticabal, v.23, n.3, p.539-546, set./dez.2003

NEVES, J. L. M et al. Avaliação de perdas invisíveis na colheita mecânica em dois fluxos de massa de cana-de-açúcar. Eng. Agric., Jaboticabal, v.26, n.3, p. 787- 794, set./dez. 2006

NUNES JUNIOR, D.; PINTO, R. S. A.; KIL, R. A. Indicadores de desempenho da agroindustria canavieira: safra 2003/2004. Ribeirão Preto: IDEA, 2005. 195p.

OLIVEIRA, C. A. A. et al. Analise do Movimento e desenvolvimento de um protótipo de cortador basal com discos bi-articulados. R. Bras. Eng. Agric. Ambiental, v.11, n.2, p.230-234, 2007.

OLIVEIRA, C. A. A. Modelagem e validação experimental de um cortador basal com discos segmentados. 2003.110p. Tese (Doutorado). Universidade de Campinas.

PERSON, S. Mechanics of cutting plant material. Michigan: American Society of Agricultural Engineers, 1987.288p.

PROJETO CALYPSO. Cana. Disponível em <http//www.projetocalypso.com.br/cana htm> Acesso em: 23 maio 2007, 21h15min.

RIDGE, D. R.; DICK, R. G. Soil intake with cane during chopper harvesting: minimizing the problem. In: AUSTRALIAN SOCIETY OF SUGAR CANE TECHNOLOGISTS, v.14, Mackay, Proceedings... p.25-30, 1992.

RIDGE,D.R. Minimizing the problem of soil in chopper harvester cane. In: AUSTRALIAN SOCIETY OF SUGAR CANE TECHNOLOGISTS, v.14,Proceedings... Manila, v.2, p.315-323, 1980.

RIPOLI , T. C. C.; RIPOLI, M.L.C. Biomassa de cana-de-açúcar: colheita, energia e ambiente. Piracicaba: Barros \& Marques, 2004. 302 p.

RIPOLI, T. C .C. Ensaio \& certificação de máquinas para colheita de cana-de-açúcar. In: MIALHE, L. G. Máquinas agrícolas: ensaios \& certificação. Piracicaba: Fundação de Estudo "Luiz de Queiroz", 1996. cap.13, p.635-73.

RIPOLI, T. C. C.; MIALHE, L. G. Custos de colheita da cana-de-açúcar no estado de São Paulo, 1981/82. Alcool \& Açúcar, v.2, n.2, p. 18-26. 1982.

RIPOLI, T. C. C; BALASTREIRE, L. A. Contribuição ao estudo do sistema de colheita mecanizada da cana de açúcar. Brasil açucareiro,v.87, n.4, p11-17, abr.1976. 
RODRIGUES, E. B. Comparação técnico-econômica da colheita de cana-de-açúcar na região de Bandeirantes-PR. 2008. 27p. Dissertação (Mestrado em Agronomia). Centro de Ciências Agrárias, Programa de Pós-Graduação em Agronomia. Universidade Estadual de Londrina.

SALVI, J. V. Qualidade do corte de base de colhedoras de cana-de-açúcar. 2006. 87p. Dissertação (Mestrado Agronomia) - Escola Superior de Agricultura "Luiz de Queiroz". Universidade de São Paulo. Piracicaba.

SEGATO, S. V. et al. Atualização em produção de cana-de-açúcar. Piracicaba: CP2, 2006. 69p.

SILVA, R. P.da et al. Controle estatístico aplicado ao processo de colheita mecanizada de cana-de-açúcar. Eng. Agric., Jaboticabal, v.28, n.2, p.292-304, abr/jun. 2008

SOUZA, M. de et.al. Sistemas de colheita e manejo da palhada de cana-de-açúcar. Pesq. Agropec.bras. Brasília, v.40, n.3, p.271-278, mar.2005

TOLEDO, P. E. N. Avaliação do potencial de uso das colhedeiras de cana de açúcar no Estado de São Paulo. Informações econômicas, v.21, n.6. p.13-20, jun.1991.

UENO, N.; IZUME, H. Sugar Loss due to mechanical harvesting. Conforme International Society of Sugar Cane Technologists. 21, 1995. New Delhi. Proceedings...New Delphi, 1995, p.274-285.

VOLPATO, C. E. S.; BRAUNBECK, O. A.; OLIVEIRA,C. A. A. Desenvolvimento e avaliação de um protótipo de cortador de base para a colhedoras de cana-de-açúcar. Revista Brasileira de Engenharia Agrícola e Ambiental, Campina Grande, v.6, n.2; p.345-8, 2002.

VOLPATO, J. L. M. Otimizaçãode um cortador de base flutuante para seguimento do perfil de solo em colhedoras de cana-de-açúcar. 2001.204p. Tese (Doutorado em Engenharia Agrícola) - Faculdade de Engenharia Agrícola, Universidade Estadual de Campinas.

VOLPATO, C. E. S.; BRAUNBECK, O. A.;OLIVEIRA, C. A. A. Desenvolvimento e avaliação de um protótipo de cortador base para colhedoras de cana-de-açúcar. Revista Brasileira de Engenharia Agrícola e Ambiental, Campina Grande,v.6,n.2,p.345348,2002 .

YOUNGER, J. A. Quality cane and extraneous matter. In: International Society Of Sugarcane Technologists, 17., 1980, Manila. Proceedings... Manila: International Society of sugarcane technologists, 1980.v.1, p.885-90. 
